This item was submitted to Loughborough's Research Repository by the author.

Items in Figshare are protected by copyright, with all rights reserved, unless otherwise indicated.

\title{
Effects of vertical and side-alternating vibration training on fall risk factors and bone turnover in older people at risk of falls
}

\section{PLEASE CITE THE PUBLISHED VERSION}

http://dx.doi.org/10.1093/ageing/afu136

\section{PUBLISHER}

Oxford University Press on behalf of the British Geriatrics Society (@ The Author 2014)

VERSION

AM (Accepted Manuscript)

\section{PUBLISHER STATEMENT}

This work is made available according to the conditions of the Creative Commons Attribution-NonCommercialNoDerivatives 4.0 International (CC BY-NC-ND 4.0) licence. Full details of this licence are available at: https://creativecommons.org/licenses/by-nc-nd/4.0/

\section{LICENCE}

CC BY-NC-ND 4.0

\section{REPOSITORY RECORD}

Corrie, Heather, Katherine Brooke-Wavell, Neil Mansfield, Alison Cowley, Robert Morris, and Tahir Masud. 2014. "Effects of Vertical and Side-alternating Vibration Training on Fall Risk Factors and Bone Turnover in Older People at Risk of Falls". Loughborough University. https://hdl.handle.net/2134/16699. 
Effects of vertical and side-alternating vibration training on fall risk factors and bone turnover in older people at risk of falls

Heather Corrie ${ }^{1}$, Katherine Brooke-Wavell ${ }^{1}$, Neil J. Mansfield ${ }^{2}$, Alison Cowley ${ }^{3}$, Robert Morris $^{3}$, Tahir Masud ${ }^{3}$

${ }^{1}$ School of Sport, Exercise and Health Sciences, Loughborough University, Loughborough, UK

${ }^{2}$ Design School, Loughborough University, Loughborough, UK

${ }^{3}$ Healthcare for Older People, Nottingham University Hospitals NHS Trust, Hucknall Road, Nottingham NG5 1PB, UK

Address correspondence to: $\mathrm{K}$. Brooke-Wavell.

Tel: (+44) 01509222749.

Email: k.s.f.brooke-wavell@lboro.ac.uk

Key words

- Whole body vibration

- Muscle function

- Falls

- Bone turnover

- Older people

Key points

- Older people were allocated to 12 weeks of vertical, side-alternating or sham vibration alongside a falls prevention programme

- Fall risk factors improved in the sham vibration with usual care group

- There were greater increases in leg power with vertical than sham vibration

- Bone turnover increased in vertical and side-alternating vibration groups relative to the sham vibration group

- Whole body vibration did not provide any benefit to balance or fall risk factors beyond usual care 


\begin{abstract}
Background: Whole body vibration training may improve neuromuscular function, falls risk and bone density, but previous studies have had conflicting findings.
\end{abstract}

Objective: This study aimed to evaluate the influence of vertical and side-alternating vibration on musculoskeletal health in older people at risk of falls.

Design: Single blind randomised controlled trial comparing vibration training to sham vibration in addition to usual care.

Participants: Participants were 61 older people (37 women and 24 men), aged $80.2 \pm 6.5 y$, referred to an outpatient falls prevention service.

Methods: Participants were randomly assigned to vertical vibration (VV), side-alternating vibration (SV) or sham vibration (Sham) in addition to the usual falls prevention programme. Participants were requested to attend three vibration sessions per week for 12 weeks, with sessions increasing to six, 1 minute bouts of vibration. Falls risk factors and neuromuscular tests were assessed, and blood samples collected for determination of bone turnover, at baseline and following the intervention.

Results: Chair stand time, timed-up-and-go time, fear of falling, NEADL index and postural sway with eyes open improved in the Sham group. There were significantly greater gains in leg power in the VV than Sham group and in bone formation in SV and VV compared to the Sham vibration group. Conversely, body sway improved less in the VV than Sham group. Changes in falls risk factors did not differ between groups.

Conclusions: Whole body vibration increased leg power and bone formation, but did not provide any additional benefits to balance or fall risk factors beyond a falls prevention programme in older people at risk of falls. 


\section{Introduction}

A substantial proportion of older people sustain falls, which in combination with low bone strength contribute to fractures and associated morbidity, reduced quality of life and increased mortality [1]. Previous fallers are more likely to fall again, so improving fall risk in previous fallers is particularly important.

Exercise is one of the few strategies that may both reduce fall risk and increase bone strength. Unfortunately, many of the people most risk of falls and fractures may be unwilling or unable to exercise. Externally applied loading as in whole body vibration is a potential alternative. Regular training by standing or exercising on a plate that vibrates at high frequency improved muscle function and bone strength in some studies, but there are some conflicting findings and gaps in the evidence [2-4]. Not all studies used a control group who received an equivalent intervention [4]. Vibration characteristics may differ in frequency, displacement and hence magnitude [5]. Vibration can be applied in different modes: vertical or side-alternating (where the plate rotates around a central axis) [5]. Few studies have compared different vibration modes [2]. Most studies were conducted either in healthy or osteoporotic older people, or in nursing home residents [2]. Healthy older people may not have elevated fall risk, whilst vibration training may compensate inactivity related losses in nursing home residents, so findings may not apply to community dwelling older people at risk of falls.

This study thus aimed to compare the effects of vertical and side-alternating vibration to sham vibration administered in addition to usual care in older people at risk of falls on measures of falls risk, neuromuscular function, balance and bone turnover.

\section{Methods}

\section{Experimental Design}

The study was a single-blind, randomised controlled trial of whole body vibration training in older people at risk of falls. Following baseline assessments, participants were randomised using a random number algorithm to receiving vertical vibration (VV), side-alternating vibration (SV), or sham vibration (Sham) in addition to usual care (see additional material for CONSORT diagram). All participants were asked to attend to participate in the intervention three times per week for 12 weeks. Assessments were repeated at week 13.

The trial was approved by the National Research Ethics Service, registered on the NHS clinical trials register and assigned an International Standard Randomised Controlled Trial Number (ISRCTN 29101534).

\section{Participants}

All men and women aged over 60 years, referred to Nottingham University Hospitals Trust Rehabilitation Unit Falls Prevention Programme during the study recruitment period were invited to participate in the study. Referral required being assessed as at risk of falling by a general practitioner, consultant geriatrician or other health professional. Exclusion criteria were contraindications to exercise or vibration, as assessed by a consultant geriatrician, and Mini-Mental State Examination (MMSE) score below 20. All participants provided written informed consent. 
We estimated that detection of improvements in neuromuscular measures (timed-up and go, muscle power) of the magnitude reported previously in older people [6] with $80 \%$ power at the $95 \%$ confidence level would require at least 11 participants per group. To allow for up to $45 \%$ loss to follow up, we sought a total of 60 participants.

\section{Measurements}

\section{Falls risk and neuromuscular function}

Measures of fall risk were assessed by health care professionals unaware of participants' intervention allocation. The timed-up-and-go test [7] involved measuring the time taken to rise from a chair, walk three metres, return and sit back down again, using the usual walking aid. Functional reach was determined by asking the participant to stand with arm extended to shoulder height parallel to a wall scale to determine normal reach, then to reach forward as far as possible to determine extended reach [8]. The chair stand test involved measuring the time taken to stand and sit back down from a firm backed chair five times, without using arms [9]. The four square step test involved stepping in four directions over a low barrier [10]. Postural hypotension was identified as a drop from lying to standing of more than $20 \mathrm{mmHg}$ in systolic or $10 \mathrm{mmHg}$ in diastolic blood pressure.

Measurements of neuromuscular function were made by the researcher who administered the interventions. Leg power was assessed using a Nottingham leg extensor leg power rig [11]. Maximal force output was determined during a counter-movement jump attempt on a custom built force plate. Static balance was assessed by recording the excursion of centre of pressure during 30s of quiet standing on the force plate. Measurements were repeated with eyes open and closed; both on a firm and compliant surface.

Reported coefficients of variation for timed-up-and-go, chair stand, leg power and jump tests were $5.28 \%, 5.1 \%, 6.5 \%$ and $3.6 \%$ respectively $[12,13]$.

\section{Bone turnover}

Venous blood samples were collected in the morning and serum analysed for procollagen type I Nterminal peptide (P1NP) as a marker of bone formation (Roche diagnostics UK Ltd, inter-assay CV 3.8-4.2\%) and isomerised C-terminal telopepide of type I collagen (CTX) as a marker of bone resorption (Roche diagnostics UK Ltd, inter-assay CV 1.6-4.3\%).

\section{Questionnaires}

Functional independence was assessed using the Nottingham extended activities of daily living index (NEADL) [14]. Quality of life was assessed using the medical outcomes study 36 item short form health survey (SF-36) [15], fear of falling using falls efficacy scale (FES) [16] and physical activity using the physical activity scale for the elderly (PASE) [17]. Comorbidities and medication use were summarised using comorbidity index [18] and medication related comorbidity index [19], both modified by updating medications.

\section{Interventions}

All participants received the usual falls prevention programme, which consisted six weekly visits to the unit, each including a one hour exercise class based on the Otago Exercise Programme [20] and 
information relevant to falls (home safety, medication, footwear, healthy eating and advice on vision and hearing tests) based on NICE guidance [21].

In addition, all participants were requested to attend the unit for a total of three visits per week for 12 weeks for vibration sessions. These involved standing upon a vibration platform, without shoes, with bent knees. The movement of each platform was quantified using a triaxial accelerometer mounted to the platform surface with beeswax. Each session consisted of several brief bouts, each separated by one minute of rest. Participants typically increased from two to four 30s bouts in week 1, up to six 1-minute bouts by week 8. Participants were asked to stop the bout if the training became unpleasant, and only increased training duration if they had completed the previous session without adverse symptoms.

Participants were blinded to their intervention allocation and sessions were conducted so that participants did not see other participants training, so were not able to speculate on their allocation by comparing the movement experienced.

\section{Vertical vibration}

The VV group used a Power Plate Next Generation device (Power Plate International Limited), set to a nominal frequency of $30 \mathrm{~Hz}$ and displacement setting of "Low". This yielded a measured frequency of $28.4 \mathrm{~Hz}$, peak-to-peak displacement of $1.3 \mathrm{~mm}$ and magnitude 15 m.s ${ }^{-2}$ r.m.s. acceleration (1.5g).

\section{Side-alternating vibration}

The SV group used a Galileo 2000 device (Novotech GmbH), set to a nominal frequency of $30 \mathrm{~Hz}$ on foot position 1. This yielded a measured frequency of $29.8 \mathrm{~Hz}$, peak-to-peak displacement at second toe of $2.9 \mathrm{~mm}$ and magnitude $36 \mathrm{~m} . \mathrm{s}^{-2}$ r.m.s. acceleration (3.6g). The motion comprised a rotational roll oscillation around a central pivot.

\section{Sham vibration}

The Sham group stood on the stationary Power Plate device, with a low frequency sound being delivered through a hidden loudspeaker to simulate the sound of a moving vibration platform.

\section{Statistical analysis}

Positively skewed variables were logarithmically transformed prior to analysis. Responses were compared between groups using analysis of covariance (ANCOVA) of post intervention values with pre-intervention values and gender as covariates to estimate the mean effect of each intervention relative to usual care. Planned contrasts were used to compare effect sizes in VV and SV groups to those in the sham group. To test for a difference in response between genders, a gender $\mathrm{x}$ group interaction term was included. Where this interaction term was not statistically significant, analysis was conducted without this term. We hypothesised that pharmaceutical effects may predominate on bone turnover in users of osteoporosis medication, so analyses of bone turnover were repeated with these participants excluded. All statistical analyses were conducted using SPSS version 19 (IBM Statistics). 


\section{Results}

\section{Participant characteristics}

Of the 109 people invited, 81 (74\%) were willing to participate. Of these, 20 people did not meet inclusion criteria (3 with MMSE scores $<20 ; 12$ with contraindications to exercise or vibration), whilst 5 were unable to attend because of transport requirements.

Of the 61 study participants, 39\% were male; whilst only $15 \%$ of non-participants were male. Participants were similar to non-participants in age (median 81 years in both groups). 85\% of participants lived in their own home and the remainder in warden-aided accommodation. 59\% were cared for by a spouse or other friend or relative. The majority used a walking aid: stick (61\%), two sticks (3\%), walking frame (15\%) or wheelchair (2\%).

The baseline characteristics of the three intervention groups are summarised in Table 1 . The proportion of male participants differed between groups, ranging from $20 \%$ in the Sham group to $60 \%$ in the VV group. Other characteristics were similar between groups.

\section{Adherence}

Two participants in each group were lost to follow up. One participant declined to attend without giving a reason, whilst five participants were admitted to hospital following falls $(n=3)$, myocardial infarction $(n=1)$ and chest infection $(n=1)$.

Of the six prescribed falls prevention programme sessions, participants in VV, SV and Sham groups attended on average 5.5, 5.5 and 5.2 sessions respectively. The total duration of vibration training completed was $114.6 \pm 43.3,135.0 \pm 27.4$ and $145.3 \pm 19.4$ minutes respectively.

Three participants from VV, and one from SV, discontinued the intervention, due to injuries from a fall, and deterioration of pre-existing arthritis, oedema and back ache. In addition, attendance was reduced due to bereavement $(n=3)$ and illness unrelated to the intervention $(n=1)$. Four participants reported transient discomfort during vibration (1 in knee and 1 calf in both SV and VV group)

\section{Changes in sham vibration group}

The Sham group showed significant improvements in chair stand time, timed-up-and-go time, FES, NEADL index, anteroposterior and mediolateral sway with eyes open (all $\mathrm{P}<0.05$; Figure 1 ). Leg power, counter movement jump force, functional reach, sway with eyes closed, PASE score and bone turnover did not change significantly.

\section{Differences in response between groups}

Leg power increased more in VV than Sham (by 23\%, $\mathrm{P}=0.044$; Figure 1), but countermovement jump force changes did not differ significantly between groups (Table 2, Supplementary Table).

Mediolateral sway with eyes open declined in Sham and SV but not VV (Figure 1), such that sway improved significantly less in the VV than Sham group (Table 2). 30s sway measurements with eyes closed, and eyes open on foam, were completed by 40 and 21 participants respectively and there were no significant changes in these conditions. Changes in fall risk measurements, and measures of physical function and quality of life did not differ between groups (Figure 1, Table 2, Supplementary Table). 
Blood samples were obtained from $74 \%$ of participants for assessment of bone turnover. Overall, vibration did not significantly influence bone turnover. Once results from 6 participants taking osteoporosis medication were excluded, SV and VV had significantly greater improvements in serum P1NP than Sham (by 35\%, P=0.008 and 26\%, P=0.028 respectively; Table 2, Figure 1, Supplementary Table) whilst there were no differences in CTX.

There were no significant gender x group interactions, indicating that vibration training effects did not differ between men and women. Post hoc tests showed no differences in effects between SV and VV groups.

\section{Discussion}

Whole body vibration was well tolerated in older people at risk of falls. In addition to the improvements seen with usual care, 12 weeks of vibration training produced some modest benefits, increasing bone formation, whilst vertical vibration improved leg power. However, vibration training did not benefit fall risk factors, with less improvement in sway in the vertical vibration than sham vibration group.

Adherence to the intervention was good, with vertical, rotation and sham vibration groups attending 77, 87 and $90 \%$ of prescribed sessions respectively. Although compliance was lowest in the vertical vibration group, this was largely a result of 3 individuals discontinuing the intervention, following deterioration of existing medical conditions.

A number of improvements were seen in the sham vibration plus usual care group, including measures of falls risk, leg power, postural sway, physical activity, independence and quality of life. Whilst these benefits may be consequences of the fall prevention programme, the study was not designed to evaluate the fall prevention programme and it is possible that greater familiarity with the measurements at the post intervention visit could contribute to the apparent improvements.

Vertical vibration improved leg power more than usual care, with the treatment effect being substantial in magnitude ( 23\%). This finding is consistent with previous studies that have reported improvements in strength and/or power in healthy community and institution dwelling older women and men [22-25]. Lower limb power is related to functional performance in older people [11] and this improvement in muscle power could benefit activities where leg power may be limiting, such as to stair ascent/descent, although there were no improvements in measures of dynamic balance.

Neither side-alternating nor vertical vibration improved postural sway in this study, in contrast to previous research: a meta-analysis of previous studies showed improvement with side-alternating, but not vertical, vibration [26]. Few participants, however, completed sway measurements in more challenging conditions, which may be more discriminative of falls [27].

Vibration training did not significantly improve any of the clinical fall risk factors assessed in this study, relative to attending a falls prevention programme alone. Although one previous study reported no benefit in nursing home residents [28], several other studies have reported improvements in fall risk factors following a vibration intervention in community and institution dwelling older people [6, 29, 30] although only one of these studies used a control intervention demonstrated to reduce fall risk [30]. It is possible that the falls prevention programme was as 
effective as vibration. Alternatively, it is possible that in this group with a high prevalence of comorbidities, muscle function was not the factor that limited performance in these clinical tests.

A novel finding is that vibration training increased bone formation. Previous studies reported no effect on bone turnover in postmenopausal women [31-33], despite increased BMD in one study [33]. The previous trials had longer duration, and an increase in bone formation might occur only transiently in adapting to a novel stimulus and subside once skeletal adaptation has occurred. Earlier studies suggested that vibration training could increase hip bone density [3], although several large recent trials, involving different vibration modes and magnitudes, reported no significant effects in postmenopausal women [32, 34, 35].

A strength of this study is the inclusion of a sham vibration plus usual care group. This provides strong evidence that changes seen were due to the vibration. Furthermore, adherence was good, with $90 \%$ of participants attending post intervention assessments and we employed an intention-totreat analysis. There are also several weaknesses. The sample size was modest, so changes with smaller effect sizes may not have been detected in this study. Participants may not have fasted prior to blood sampling, which may have increased the variance in bone marker measurements, most likely reducing the likelihood of detecting changes in bone metabolism. The duration of the study was not long enough to expect changes in bone mineral density or fall incidence. The participation of all participants in a falls prevention programme allows quantification of the additional benefit of vibration, but may underestimate vibration effects relative to no intervention.

In conclusion, this study demonstrated that whole body vibration training was feasible and produced modest benefits in addition to a falls prevention programme in older people at risk of falls: increased bone formation and increased leg power from vertical vibration, which may contribute to improved physical function.

\section{Declaration of sources of funding}

This project was supported by the National Osteoporosis Society, UK and British Geriatrics Society. The vibration platforms used in the study were loaned by the manufacturers. The project funders played no role in the design, execution, analysis and interpretation of data, or reporting of the study.

\section{References}

1. $\quad$ Masud T, Morris RO. Epidemiology of falls. Age Ageing 2001;30-S4:3-7.

2. Merriman $\mathrm{H}$, Jackson $\mathrm{K}$. The effects of whole-body vibration training in aging adults: a systematic review. J Geriatr Phys Ther 2009;32(3):134-45.

3. Slatkovska L, Alibhai SMH, Beyene J, Cheung AM. Effect of whole-body vibration on BMD: a systematic review and meta-analysis. Osteoporos Int 2010;21(12):1969-1980.

4. Brooke-Wavell K, Mansfield NJ. Risks and benefits of whole body vibration training in older people. Age Ageing 2009;38(3):254-255.

5. Rauch F, Sievanen H, Boonen S, et al. Reporting whole-body vibration intervention studies: Recommendations of the International Society of Musculoskeletal and Neuronal Interactions. J Musculoskelet Neuronal Interact 2010;10(3):193-198.

6. Bruyere O, Wuidart MA, Di Palma E, et al. Controlled whole body vibration to decrease fall risk and improve health-related quality of life of nursing home residents. Arch Phys Med Rehabil 2005;86(2):303-307. 
7. Podsiadlo D, Richardson S. The Timed Up And Go - A Test Of Basic Functional Mobility For Frail Elderly Persons. J Am Geriatr Soc 1991;39(2):142-148.

8. Duncan PW, Weiner DK, Chandler J, Studenski S. Functional Reach - A New Clinical Measure Of Balance. J Gerontol 1990;45(6):M192-M197.

9. Guralnik JM, Seeman TE, Tinetti ME, Nevitt MC, Berkman LF. Validation and use of performance measures of functioning in a non- disabled older population: MacArthur studies of successful aging. Aging Clin Exp Res 1994;6(6):410-419.

10. Dite W, Temple VA. A clinical test of stepping and change of direction to identify multiple falling older adults. Archives Phys Med Rehabil 2002;83(11):1566-1571.

11. Bassey EJ, Fiatarone MA, Oneill EF, Kelly M, Evans WJ, Lipsitz LA. Leg Extensor Power And Functional Performance In Very Old Men And Women. Clin Sci 1992;82(3):321-327.

12. Rittweger J, Schiessl H, Felsenberg D, Runge M. Reproducibility of the jumping mechanography as a test of mechanical power output in physically competent adult and elderly subjects. J Am Geriatr Soc 2004;52(1):128-131.

13. Bassey EJ, Short AH. A New Method For Measuring Power Output In A Single Leg Extension - Feasibility, Reliability And Validity. Eur J Appl Physiol Occ Physiol 1990;60(5):385390.

14. Nouri FM, Lincoln NB. An extended activities of daily living scale for stroke patients. Clin Rehabil 1987;1:301-305.

15. Ware JE, Sherbourne CD. The Medical Outcomes Study (MOS) 36-item short-form health survey (SF-36): I. Conceptual framework and item selection. Med Care 1992;30:473-483.

16. Tinetti ME, Richman D, Powell L. Falls efficacy as a measure of fear of falling. J Gerontol 1990;45(6):P239-P243.

17. Washburn RA, Smith KW, Jette AM, Janney CA. The Physical-Activity Scale For The Elderly (Pase) - Development And Evaluation. J Clin Epidemiol 1993;46(2):153-162.

18. Charlson ME, Pompei P, Ales KL, MacKenzie CR. A new method of classifying prognostic comorbidity in longitudinal studies: development and validation. J Chronic Dis 1987;40(5):373-383. 19. Von Korff M, Wagner EH, Saunders K. A chronic disease score from automated pharmacy data. J Clin Epidemiol 1992;45(2):197-203.

20. Campbell AJ, Robertson MC, Gardner MM, Norton RN, Tilyard MW, Buchner DM. Randomised controlled trial of a general practice programme of home based exercise to prevent falls in elderly women. Br Med J 1997;315:1065-1069.

21. National Institute for Clinical Excellence. Clinical Practice Guideline for the Assessment and Prevention of Falls in Older People: Guidelines Commissioned by the National Institute for Clinical Excellence (NICE): Royal College of Nursing; 2004.

22. Bogaerts ACG, Delecluse C, Claessens AL, Troosters T, Boonen S, Verschueren SMP. Effects of whole body vibration training on cardiorespiratory fitness and muscle strength in older individuals (a 1-year randomised controlled trial). Age Ageing 2009;38(4):448-454.

23. Roelants M, Delecluse C, Verschueren SM. Whole-body-vibration training increases kneeextension strength and speed of movement in older women. J Am Geriatr Soc 2004;52(6):901-908.

24. Rees S, Murphy A, Watsford M. Effects of vibration exercise on muscle performance and mobility in an older population. J Aging Phys Act 2007;15:367-381.

25. Bautmans I, Van Hees E, Lemper J-C, Mets T. The feasibility of whole body vibration in institutionalised elderly persons and its influence on muscle performance, balance and mobility: a randomised controlled trial. BMC Geriatr 2005;5:17.

26. Rogan S, Hilfiker R, Herren K, Radlinger L, de Bruin ED. Effects of whole-body vibration on postural control in elderly: a systematic review and meta-analysis. BMC Geriatr 2011;11(1):72. 27. Merlo A, Zemp D, Zanda E, Rocchi S, Meroni F, Tettamanti M, et al. Postural stability and history of falls in cognitively able older adults: The Canton Ticino study. Gait Posture 2012;36(4):662-666. 
28. Beaudart C, Maquet D, Mannarino M, Buckinx F, Demonceau M, Crielaard J-M, et al. Effects of 3 months of short sessions of controlled whole body vibrations on the risk of falls among nursing home residents. BMC Geriatr 2013;13(1):42.

29. Furness TP, Maschette WE. Influence Of Whole Body Vibration Platform Frequency On Neuromuscular Performance Of Community-Dwelling Older Adults. J Strength Conditioning Res 2009;23(5):1508-1513.

30. Pollock RD, Martin FC, Newham DJ. Whole-body vibration in addition to strength and balance exercise for falls-related functional mobility of frail older adults: a single-blind randomized controlled trial. Clin Rehabil 2012;26(10):915-923.

31. Bemben DA, Palmer IJ, Bemben MG, Knehans AW. Effects of combined whole-body vibration and resistance training on muscular strength and bone metabolism in postmenopausal women. Bone 2010;47(3):650-656.

32. Iwamoto J, Sato Y, Takeda T, Matsumoto H. Whole body vibration exercise improves body balance and walking velocity in postmenopausal osteoporotic women treated with alendronate: Galileo and Alendronate Intervention Trail (GAIT). J Musculoskelet Neuronal Interact 2012;12(3):136-143.

33. Verschueren SMP, Roelants M, Delecluse C, Swinnen S, Vanderschueren D, Boonen S. Effect of 6-month whole body vibration training on hip density, muscle strength, and postural control in postmenopausal women: a randomized controlled pilot study. J Bone Miner Res 2004;19(3):352-359.

34. Slatkovska L, Alibhai SMH, Beyene J, Hu H, Demaras A, Cheung AM. Effect of 12 Months of Whole-Body Vibration Therapy on Bone Density and Structure in Postmenopausal WomenA Randomized Trial. Ann Int Med 2011;155(10):668-679.

35. Verschueren SMP, Bogaerts A, Delecluse C, et al. The Effects of Whole-Body Vibration Training and Vitamin D Supplementation on Muscle Strength, Muscle Mass, and Bone Density in Institutionalized Elderly Women: A 6-Month Randomized, Controlled Trial. J Bone Miner Res 2011;26(1):42-49. 
Table 1: Characteristics of participants in sham vibration (Sham), side-alternating vibration (SV) and vertical vibration (VV) groups: number (\%), mean \pm standard deviation or median (interquartile range)

\begin{tabular}{|c|c|c|c|}
\hline & $\begin{array}{l}\text { Sham } \\
\mathrm{n}=20\end{array}$ & $\begin{array}{c}\mathrm{SV} \\
\mathrm{n}=20\end{array}$ & $\begin{array}{c}\mathrm{VV} \\
\mathrm{n}=21\end{array}$ \\
\hline \multicolumn{4}{|l|}{ Number (\%) } \\
\hline Female & $16(80 \%)$ & $8(40 \%)$ & $13(62 \%)$ \\
\hline Taking osteoporosis medication & $3(15 \%)$ & $5(25 \%)$ & $3(14 \%)$ \\
\hline Postural hypotension & $4(20 \%)$ & $1(5 \%)$ & $0(0 \%)$ \\
\hline \multicolumn{4}{|l|}{ Mean \pm standard deviation } \\
\hline Age & $79.1 \pm 7.8$ & $79.5 \pm 5.7$ & $81.9 \pm 5.7$ \\
\hline Weight (kg) & $64.8 \pm 10.2$ & $70.9 \pm 18.7$ & $70.7 \pm 14.7$ \\
\hline CMJ force (N/kg body weight) & $7.8 \pm 2.4$ & $7.2 \pm 3.3$ & $7.3 \pm 2.9$ \\
\hline Leg power (W/kg body weight) & $0.56 \pm 0.26$ & $0.56 \pm 0.45$ & $0.52 \pm 0.24$ \\
\hline Functional reach $(\mathrm{cm})$ & $16.0 \pm 5.9$ & $13.8 \pm 6.2$ & $13.7 \pm 6.6$ \\
\hline NEADL score & $41.4 \pm 12.0$ & $40.7 \pm 14.4$ & $41.2 \pm 10.8$ \\
\hline Fear of falling score & $34.4 \pm 19.9$ & $31.8 \pm 19.8$ & $30.6 \pm 12.5$ \\
\hline Four square step test score & $2.15+1.1$ & $1.85+1.0$ & $1.81+0.9$ \\
\hline MMSE score & $27.8 \pm 2.8$ & $28.3 \pm 2.2$ & $28.6 \pm 2.5$ \\
\hline PASE score & $51.7 \pm 31.0$ & $57.4 \pm 31.8$ & $58.1 \pm 26.0$ \\
\hline \multicolumn{4}{|l|}{ SF-36 scores } \\
\hline Physical functioning & $35 \pm 27$ & $32 \pm 20$ & $31 \pm 20$ \\
\hline Role limitations & $28 \pm 28$ & $28 \pm 37$ & $19 \pm 19$ \\
\hline Bodily pain & $53 \pm 28$ & $64 \pm 31$ & $60 \pm 28$ \\
\hline Social functioning & $53 \pm 33$ & $58 \pm 34$ & $49 \pm 33$ \\
\hline Mental health & $59 \pm 23$ & $71 \pm 23$ & $71 \pm 25$ \\
\hline $\begin{array}{l}\text { Role limitations due to emotional } \\
\text { problems }\end{array}$ & $55 \pm 41$ & $67 \pm 39$ & $71 \pm 38$ \\
\hline Vitality energy or fatigue & $28 \pm 17$ & $44 \pm 25$ & $36 \pm 17$ \\
\hline Health compared to last year & $31 \pm 27$ & $48 \pm 28$ & $50 \pm 30$ \\
\hline \multicolumn{4}{|l|}{ Median (interquartile range) } \\
\hline Number of medications & $4.0(3.0-6.0)$ & $6.0(3.3-8.0)$ & $4.5(3.0-5.0)$ \\
\hline Medication related comorbidity index & $3.5(3.0-4.8)$ & $4.5(2.3-6.8)$ & $3.0(2.0-6.9)$ \\
\hline Comorbidity Index & $2.5(1.0-4.0)$ & $2.5(1.0-3.8)$ & $2.0(1.3-3.8)$ \\
\hline Timed-up-and-go time (s) & $21(16-32)$ & $22(17-34)$ & $28(18-42)$ \\
\hline Serum bone turnover markers & $n=14$ & $n=13$ & $n=14$ \\
\hline $\mathrm{CTX}(\mu \mathrm{g} / \mathrm{L})$ & $0.42(0.23-0.65)$ & $0.33(0.27-0.70)$ & $0.26(0.16-0.41)$ \\
\hline $\mathrm{P} 1 \mathrm{NP}(\mu \mathrm{g} / \mathrm{L})$ & $51(39-72)$ & $43(36-79)$ & $30(25-60)$ \\
\hline Postural sway (eyes open) & $n=17$ & $n=20$ & $n=20$ \\
\hline Sway distance y (mm) & $180(133-302)$ & $176(141-281)$ & $183(110-216)$ \\
\hline Sway distance $\mathrm{x}(\mathrm{mm})$ & 317 (253-627) & $385(282-536)$ & $269(212-470)$ \\
\hline Sway speed (mm/s) & $13(10-24)$ & $16(11-21)$ & $12(8-18)$ \\
\hline Postural sway (eyes closed) & $n=15$ & $n=15$ & $n=15$ \\
\hline Sway distance y (mm) & $213(156-405)$ & $280(172-406)$ & 287 (166-392) \\
\hline Sway distance $\mathrm{x}(\mathrm{mm})$ & $511(372-792)$ & $657(444-740)$ & $427(319-761)$ \\
\hline Sway speed $(\mathrm{mm} / \mathrm{s})$ & $\begin{array}{c}20(16-33) \\
n=14\end{array}$ & $\begin{array}{c}25(18-30) \\
n=9\end{array}$ & $\begin{array}{c}22(14-29) \\
n=9\end{array}$ \\
\hline Chair stand time (s) & $23(20-30)$ & $20(17-30)$ & $27(19-46)$ \\
\hline
\end{tabular}


Table 2: Treatment effect for side-alternating vibration (SV) and vertical vibration (VV) relative to sham vibration. Calculated from ANCOVA of post-intervention values with preintervention values and gender as covariates.

\begin{tabular}{|c|c|c|}
\hline Arithmetic means & SV & VV \\
\hline $\begin{array}{l}\text { Functional reach } \\
(\mathrm{cm})\end{array}$ & $-0.8(-5.0-3.3)$ & $-2.0(-5.8-1.9)$ \\
\hline $\begin{array}{l}\text { Maximum countermovement jump force } \\
\text { (N/ kg bodyweight) }\end{array}$ & $0.007(-1.673-1.688)$ & $-1.014(-2.555-0.527)$ \\
\hline $\begin{array}{l}\text { Nottingham extended activities of daily living } \\
\text { index }\end{array}$ & $-1.6(-6.6-3.4)$ & $-2.3(-6.9-2.4)$ \\
\hline Fear of falling (FES) score & $3.16(-5.98-12.31)$ & $1.25(-7.24-9.73)$ \\
\hline PASE & $8.1(-17.6-33.9)$ & $-2.1(-26.4-22.1)$ \\
\hline Geometric means $^{\mathrm{a}}$ & SV & VV \\
\hline Timed-up-and-go time (s) & $1.10(0.83-1.41)$ & $1.20(0.93-1.55)$ \\
\hline Chair stand time (s) & $0.98(0.69-1.41)$ & $1.26(0.89-1.82)$ \\
\hline Mean leg power (W/kg) & $1.08(0.87-1.36)$ & $1.23(1.01-1.51)^{*}$ \\
\hline \multicolumn{3}{|l|}{ Postural sway (eyes open) } \\
\hline Log sway speed & $1.12(0.95-1.35)$ & 1.29 (1.07-1.51)* \\
\hline Log anteroposterior distance & $1.20(0.98-1.48)$ & $1.20(0.98-1.48)$ \\
\hline Log mediolateral distance & $1.10(0.91-1.32)$ & $1.29(1.10-1.55)^{* *}$ \\
\hline \multicolumn{3}{|l|}{ Postural sway (eyes closed) } \\
\hline Log sway speed & $0.91(0.68-1.23)$ & $0.87(0.66-1.17)$ \\
\hline Log anteroposterior distance & $1.07(0.74-1.58)$ & $0.85(0.59-1.23)$ \\
\hline Log mediolateral distance & $0.89(0.68-1.20)$ & $0.93(0.71-1.23)$ \\
\hline \multicolumn{3}{|l|}{ Markers of bone turnover } \\
\hline Log CTX & $0.95(0.68-1.35)$ & $1.00(0.72-1.35)$ \\
\hline Log P1NP & $1.20(0.95-1.48)$ & $1.17(0.95-1.41)$ \\
\hline \multicolumn{3}{|l|}{$\begin{array}{l}\text { Markers of bone turnover (participants taking } \\
\text { osteoporosis medication excluded) }\end{array}$} \\
\hline Log CTX & $1.07(0.74-1.55)$ & $0.93(0.68-1.32)$ \\
\hline Log P1NP & 1.35 (1.10-1.70)* & $1.26(1.02-1.58)^{*}$ \\
\hline
\end{tabular}

$* \mathrm{P}<0.05 * * \mathrm{P}<0.001$

${ }^{a}$ Variables were logarithmically transformed prior to analysis so effect sizes are geometric means, which will represent multiplicative effects. 
Figure 1: Mean changes during 12 weeks of sham vibration, side-alternating vibration (SV) or vertical vibration (VV): a) timed-up-and-go time; b) chair stand time; c) leg power; d) postural sway (eyes open); e) Nottingham extended activities of daily living index; f) Falls Efficacy Scale score; g) procollagen type I N-terminal propetide (P1NP); h) telomerised C-terminal telopeptide (CTX). Error bars represent 95\% confidence intervals. * Significant difference between groups: $\mathrm{P}<0.05$ 
Vibration training, bone turnover and falls risk

a)

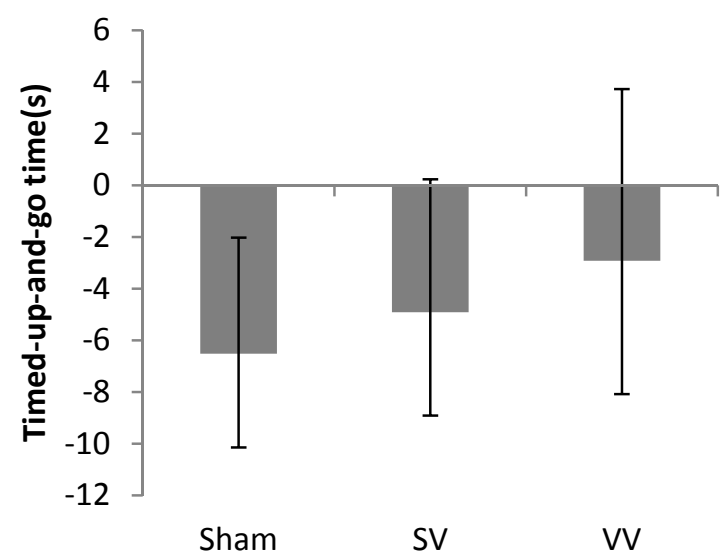

c)

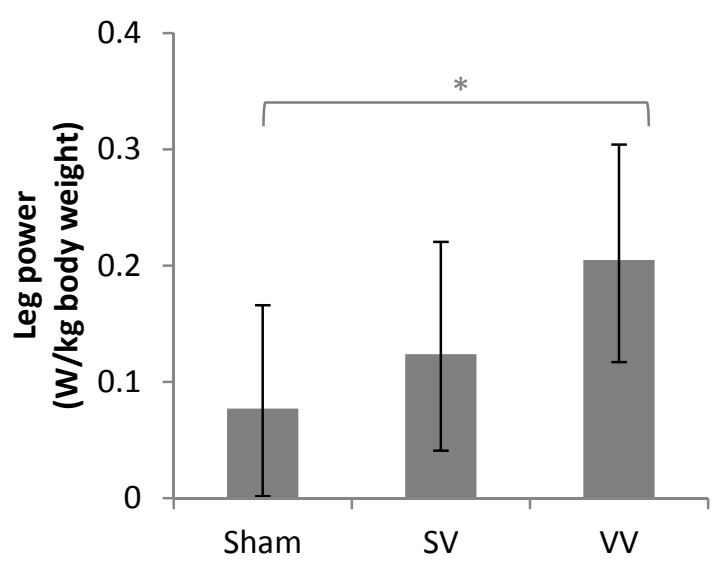

e)

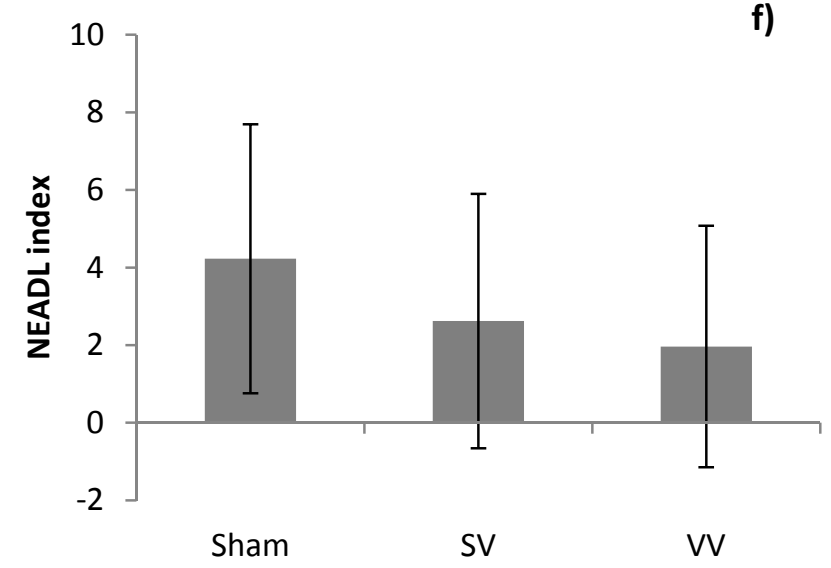

g)

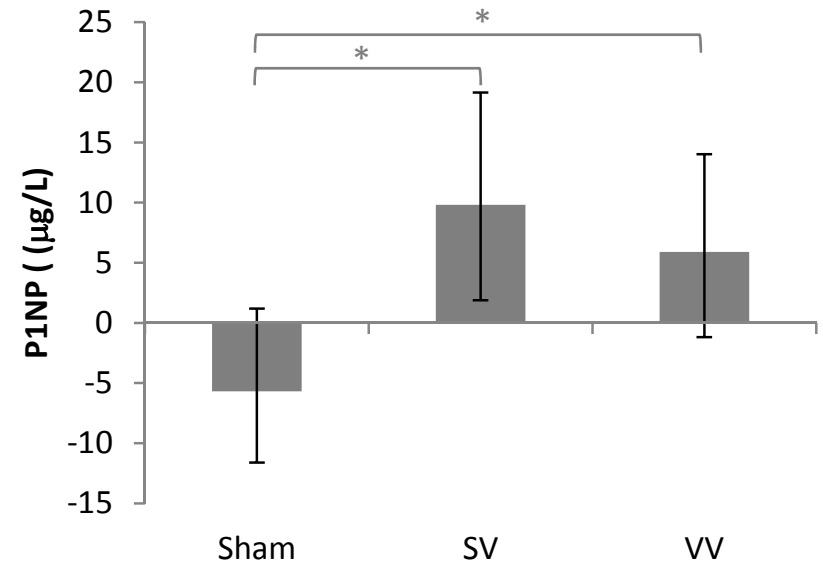

b)

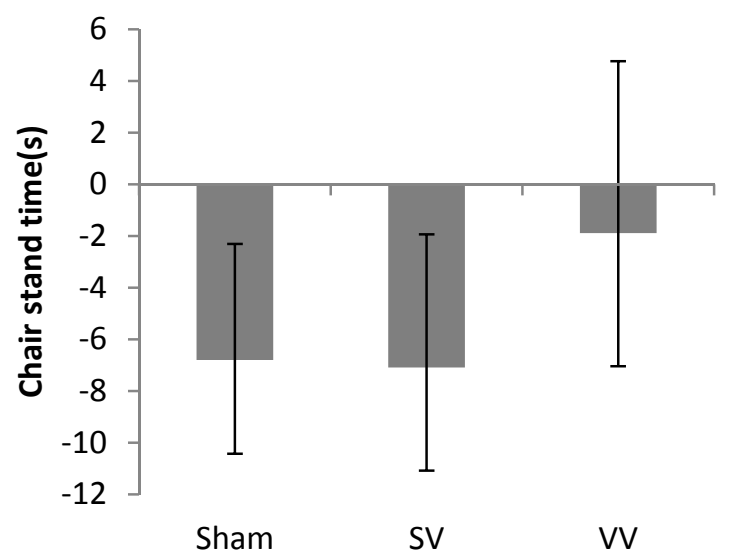

d)
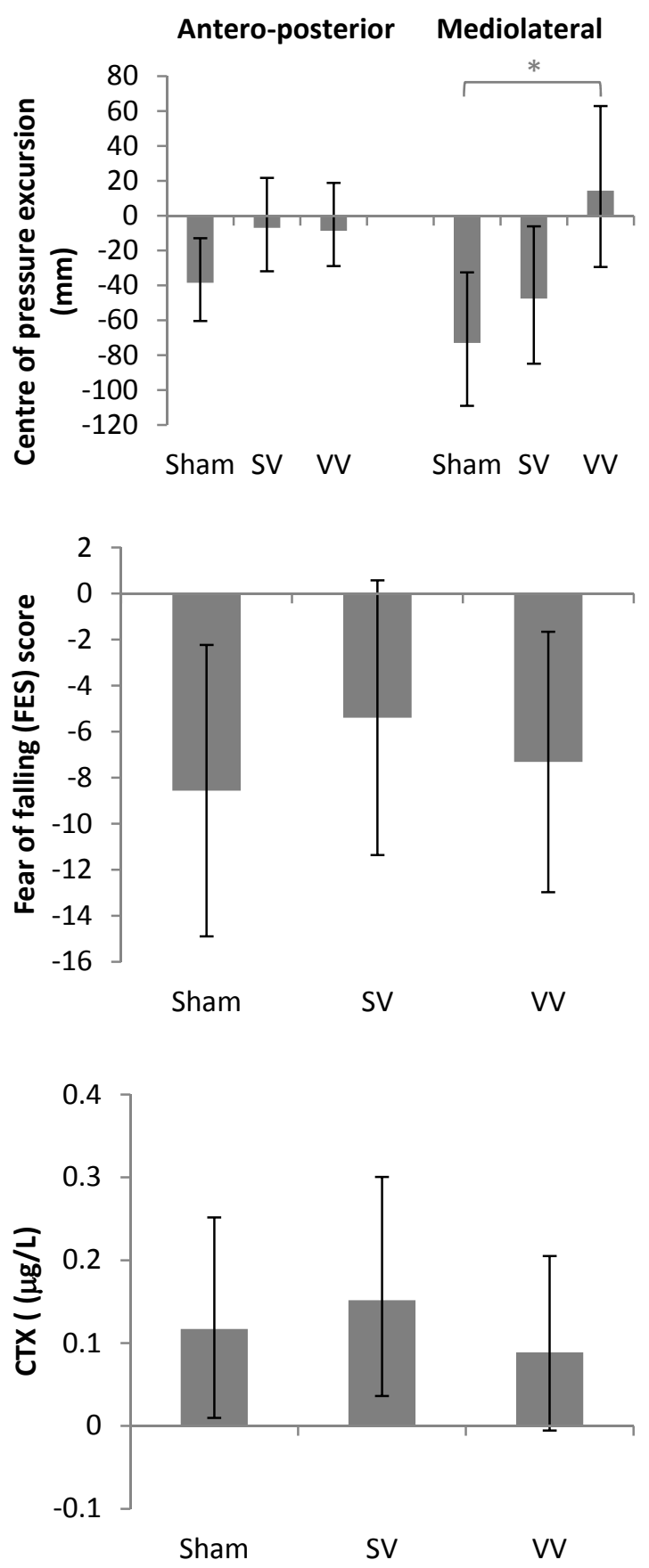